Penultimate version, to appear in Southern Journal of Philosophy in 2013. Please cite published paper.

\title{
Tensed Supervenience: a No-Go for Presentism.
}

Sam Baron

(University of Sydney)

\begin{abstract}
Recent attempts to resolve the truthmaker objection to presentism employ a fundamentally tensed account of the relationship between truth and being. On this view, the truth of a proposition concerning the past supervenes on how things are, in the present, along with how things were, in the past. This tensed approach to truthmaking arises in response to pressure placed on presentists to abandon the standard response to the truthmaker objection, whereby one invokes presently existing entities as the supervenience base for the truth of past-directed propositions. In this paper, I argue that a fundamentally tensed approach to truthmaking is implausible because it requires the existence of cross-temporal supervenience relations, which are anathema to presentism.
\end{abstract}

\section{Introduction}

Recently, presentists have attempted to resolve the truthmaker objection to presentism by adopting a fundamentally tensed account of the relationship between truth and being. On this view, roughly, the truth of a proposition concerning the past supervenes on how things are, in the present, along with how things were, in the past. More specifically, truth supervenes either on things that exist along with the properties that they instantiate or on things that existed along with the properties that they instantiated. This tensed approach to truthmaking arises in response to recent pressure placed on presentists to abandon the standard response to the truthmaker objection, whereby one invokes presently existing 
Penultimate version, to appear in Southern Journal of Philosophy in 2013. Please cite published paper.

entities to stand proxy for past things and serve as the supervenience base for the truth of past-directed propositions.

In this paper, I argue that a fundamentally tensed approach to the truthmaker objection is implausible. This is important because it suggests that the pressure placed on presentists to give up the standard response to the truthmaker objection forces them all the way toward the view that propositions concerning the past are false: a view that most presentists are unwilling to accept. I begin in $\S 2$ by outlining the truthmaker objection to presentism in more detail, along with both the standard response to that problem and the tensed truthmaking approach. In $\S 3$ I argue that the tensed approach to truthmaking is implausible because it presupposes the existence of cross-temporal relations, which are anathema to presentism. In $\S \S 4-5$ I defend this objection against some likely responses.

\section{Presentism and Supervenience}

Although there is controversy over how presentism ought to be stated, ${ }^{1}$ for current purposes I will assume that presentism is, minimally, the view according to which all and only present things exist. The challenge that truthmaker theory presents for presentism so conceived begins with the intuitive claim that truth supervenes on being, where truth supervenes on being if one cannot change the truth of a proposition, without also changing the ontology (i.e. which things exist, the properties that existing things instantiate or the relations in which they stand). Following David Lewis (who follows John Bigelow (1988, p. 133)), this broad idea can be stated as:

\footnotetext{
${ }^{1}$ For discussion, see Crisp (2004a), Crisp (2004b), Ludlow (2004), Mason (2006) and Sider (2006).
} 
Penultimate version, to appear in Southern Journal of Philosophy in 2013. Please cite published paper.

The Supervenience Principle (SP): For any proposition $P$ and any worlds $W$ and $V$, if $P$ is true in $W$ but not in $V$, then either something exists in one of the worlds but not in the other, or else some n-tuple of things stands in some fundamental relation in one of the worlds but not in the other. (Lewis 2001, p. 612)

Using SP the truthmaker objection to presentism can be set out as follows:

\section{The Truthmaker Objection}

All and only present things exist [from presentism]

Some propositions concerning the past are true [assumption]

If propositions concerning the past are true, then the truth of those propositions supervenes on what exists, the properties they instantiate and the relations in which they stand [from $\mathbf{S P}$ ]

If presentism is true, the truth of propositions concerning the past does not supervene on what exists, the properties that existing things instantiate or the relations in which they stand [assumption]

(C1) Therefore, presentism is false [from P1, P2, P3 \& P4]

$\mathrm{P} 1$ and $\mathrm{P} 3$ in the above argument follow from presentism and SP respectively. Something must be said concerning P2 and P4, however. Let's start with P4. The standard justification for P4 is the plausible idea that the past is independent of how things are in the present. In particular, it seems reasonable to suppose that the present might have been just as it is, even though the past might have been radically different (Keller 2004, p. 88, Caplan and Sanson 2011, p. 197). Hence, because the ontology of the present seems to be compatible 
Penultimate version, to appear in Southern Journal of Philosophy in 2013. Please cite published paper.

with multiple distinct permutations of the past history of the world, such ontology appears insufficient to underwrite the truth of any particular set of claims concerning how things were.

P2 by contrast is needed to preserve one of the chief advantages of presentism over other models of time, namely that presentism is supposed to be the intuitive view. It is, as David Lewis (2004b, p. 7) and Hilary Putnam (1967, p. 240) point out, the view of the man on the street (a sentiment endorsed by Bigelow (1996, p. 35), De Clercq (2006, p. 386), Kierland and Monton (2007, p. 485), Markosian (2004, p. 49), Merricks (2007, p. 140), and Zimmerman (2008, p. 211)). As Jonathan Tallent (2009b, pp. 407-408) suggests however, this advantage of presentism is seriously weakened if one is forced to reject the truth of claims concerning the past. One of our central intuitions about time is that there is a unique way that the past was and, arguably, this intuition presupposes the existence of a range of true, past-directed propositions that accurately describe the history of the world.

With this in mind, there are just three options open to the presentist for resisting the truthmaker objection. First, one might simply reject P2 and maintain that propositions concerning the past are false (see, for example, Markosian (2004, pp. 65-73) and Sider (1999)). Although there is something to be said for this way out of the difficulty, it has proved unpopular amongst presentists, due largely to its intuitive cost. Consequently, I will not dwell upon it here, except to note that if the other two options for resisting the truthmaker objection fail, then this option will be the presentist's only strategy for resolving that difficulty.

The second option for resisting the truthmaker objection is to reject P3 and maintain that propositions concerning the past are true, even though they do not strictly supervene on the ontology for their truth (see for example Kierland and Monton (2007), Baia (forthcoming) 
Penultimate version, to appear in Southern Journal of Philosophy in 2013. Please cite published paper.

and (in germ at least) Smith $\left(1999\right.$, p. 285)). ${ }^{2}$ On this view, the truth of past-directed propositions supervenes both on what exists, the properties that existing things instantiate and the relations in which they stand, and what existed along with the properties that things instantiated in the past and the relations in which things stood. ${ }^{3}$ According to Kierland and Monton (2007, p. 490) this approach "can be sloganized as: truth supervenes on being and past being" and proceeds by rejecting SP, replacing it instead with a fundamentally tensed account of the supervenience of truth on being, such as one of the following:

(Presentist TSB) For any worlds $\mathrm{W}_{1}$ and $\mathrm{W}_{2}$, let $\psi$ be the proposition that something exists in one world but not the other, or else some object instantiates a property or a relation in one world but not the other. For any proposition $\mathrm{P}$, if $\mathrm{P}$ is true in $\mathrm{W}_{1}$ but not $\mathrm{W}_{2}$, then $\psi$ or $\operatorname{WAS}(\psi)$ or $\operatorname{WILL}(\psi) .^{4}$ (Baia forthcoming).

\footnotetext{
${ }^{2}$ It is perhaps controversial to say that Kierland and Monton's brute past presentism is an instance of the general approach under consideration. Although Kierland and Monton clearly state that, on their view, propositions concerning the past supervene on past being, they take 'past being' to be a present aspect of reality. It is unclear what the authors mean by this but it seems to suggest that, on their view, past being is (something like) one big surrogate entity for the past that exists in the present. If that were correct however, then their view would simply be a form of the standard response to the truthmaker objection. But I take it that the view is supposed to be distinct to that response. So I am inclined to think that this is not what they mean but, rather, what they have in mind is something like the tensed approach advocated by Baia.

${ }^{3}$ There is an alternative formulation of this view. According to the alternative formulation, one contends that the truth of propositions concerning the past does not supervene on anything. Tallant (2009a) is one philosopher who, in recent times, defends this option. Merricks (2007, pp. 137-145) also defends something along these lines. Although this is an interesting view, I take the difficulties with such a view outlined by Keller (2004, pp. 91-93) to be conclusive and so I will not discuss the view any further here.

4 'WAS' and 'WILL' are primitive sentential tense operators that undercut the ontological force of the existential statements that occur within their scope.
} 
Penultimate version, to appear in Southern Journal of Philosophy in 2013. Please cite published paper.

(QBSP) Truth supervenes on things, how things are, and the past about things and how things were. (Kierland and Monton 2007, p. 490).

This option for resisting the truthmaker objection can be motivated by recent criticism of the third approach to resolving that argument. The third approach to resisting the truthmaker objection proceeds by rejecting $\mathrm{P} 4$, arguing that propositions concerning the past can, in fact, supervene on some feature of the presentist's ontology. In particular, the truth of past-directed propositions supervenes on presently existing 'surrogate' entities that stand proxy for past things. On this view, the existence of these surrogates necessitates the past having been a certain way and so, in virtue of this necessitation, it is not the case that there are multiple past histories compatible with the present ontology of the world. ${ }^{5}$ Rather, associated with each complete set of existing surrogates, there is just one, unique history. Thus, the presentist who endorses this view denies the central justification behind P4, by denying that the past is wholly independent of what exists, the properties that existing things instantiate and the relations in which they stand, in the sense described above.

This third approach is by far the most popular solution to the truthmaker objection endorsed by presentists, and so I will call it the standard response to that problem. ${ }^{6}$ The locus classicus of the standard response is Bigelow's tensed properties account. Consider the proposition that dinosaurs existed. According to Bigelow (1996, pp. 46-47), the truth of that proposition supervenes on a special kind of 'tensed' property, presently instantiated by the

\footnotetext{
5 In Baron (2012a), I show that such necessitation poses a significant problem for the truthmaker objection.

${ }^{6}$ This view is defended by: Bigelow (1996, pp. 46-47), Bigelow and McKinnon (forthcoming), Bourne (2006, pp. 52-61), Crisp (2007, pp. 98-105), Cameron (2011) and Keller (2004, pp. 94-102).
} 
Penultimate version, to appear in Southern Journal of Philosophy in 2013. Please cite published paper.

world: the property having being such that Dinosaurs existed, where this tensed property stands proxy for (and necessitates) the past existence of dinosaurs.

Bigelow's approach is not the only option for developing this view, however. One might also use the present historical records as the supervenience base for the truth of claims concerning the past (see Dainton (2001, pp. 80-81) for discussion). Alternatively, one might employ abstract objects to play this role, such as Craig Bourne (2006, pp. 52-61) and Tom Crisp's (2007, pp. 98-105) ersatz times (which are maximally consistent sets of tenseless propositions).

Recently, however all forms of the standard response have come under fire. In a series of papers David Sanson and Ben Caplan (2010, Caplan and Sanson 2011, pp. 199-203) argue that the entities brought in by the presentist to do truthmaking work (such as tensed properties or ersatz times) are explanatorily deficient. Following the work of Ian McFetridge (1990) and David Liggins (2005), Sanson and Caplan assume that mere supervenience is not sufficient for truthmaking. Rather, the supervenience base for the truth of a proposition must also explain why a proposition is true. So, for example, consider the proposition that a red rose exists. On the current view, the correct supervenience base for the truth of that claim appears to be the existence of red roses, because that explains why the proposition is true. It does not appear correct to say that the truth of that proposition supervenes on blue violets say, since such things appear incapable of doing the same explanatory work.

Sanson and Caplan (2010, pp. 25-30) go on to argue that the correct explanation for the truth of a proposition concerning the past involves how things were, in the past, rather than how things are with the existing surrogates. So, for example, the correct explanation for the truth of the proposition that dinosaurs existed involves how things stood with the dinosaurs: namely, that they once existed. The presently existing property having been such that dinosaurs existed does not, by contrast, appear to provide much by way of explanation 
Penultimate version, to appear in Southern Journal of Philosophy in 2013. Please cite published paper.

for the truth of that proposition. Or, rather, in so far as it does possess explanatory power, that explanatory power is entirely parasitic on the superior explanatory power of how things were with the dinosaurs (Sanson and Caplan 2010, p. 27).

A similar argument against the standard response is mounted by Trenton Merricks (2007, pp. 133-137). Rather than focusing on explanation however, Merricks focuses on 'aboutness'; the sense in which a proposition is about a particular feature of the ontology. As with Sanson and Caplan, it is Merricks' view that mere supervenience is not sufficient for truthmaking. Rather, something more is required and that something more is aboutness: a proposition must be true in virtue of the very thing(s) that a proposition appears to be about.

Although Merricks does not offer an analysis of aboutness, for which he has been criticised (Schaffer 2008, pp. 302-307, McDaniel 2011, pp. 207-211), the general idea appears intuitively compelling. As Barry Smith (1999, pp. 279-281) and Greg Restall (1996, pp. 338-339) have urged, there must be a relevance constraint of some kind on what can count as the ontological basis for the truth of a proposition, otherwise it will be all too easy to make certain propositions (such as necessary truths) true. Merricks' notion of 'aboutness' is an attempt to give shape to a constraint of this kind. If the notion of aboutness as applied to propositions (or something like it) is coherent and Merricks is correct concerning its relationship to truthmaking then, once again, propositions concerning the past ought to be true in virtue of how things were, rather than how they are with the tensed properties and the like, since that is what the relevant propositions are about.

It should be noted that not only do these two criticisms of the standard response place pressure on the presentist to seek out a further solution to the truthmaker objection, they also force presentists toward something like the tensed supervenience approach noted above. That is because, if either Sanson and Caplan or Merricks is correct, then the only adequate supervenience base for the truth of propositions concerning the past appears to be the past 
Penultimate version, to appear in Southern Journal of Philosophy in 2013. Please cite published paper.

itself. After all, that is what explains why the relevant propositions are true and, moreover, that is what those propositions appear to be about. The central question facing the presentist then is whether the supervenience of truth on past being is acceptable. For if it is not then the pressure exerted by the failure of the standard response will push presentists all the way toward rejecting P2: the claim that propositions concerning the past are true. An outcome that, as already indicated, most presentists wish to avoid.

\section{Supervenience and Cross-Temporal Relations}

Consider again the tensed approach to truthmaking. On this view, past-directed propositions supervene for their truth on things that existed in the past, along with the fundamental properties those things instantiated. In what follows I argue that the tensed approach to truthmaking faces a serious difficulty.

To grasp the problem notice first that tensed supervenience is still supervenience, and supervenience is a relation: if $a$ supervenes on $b$ then that is in virtue of some supervenience relation $R$ such that $a R b$. Consequently, if the truth of propositions concerning the past supervenes on the past itself, then there must exist cross-temporal supervenience relations that have as their relata past things.

However, most presentists deny the existence of relations of this kind because most presentists are serious presentists, where serious presentism is the view according to which past things do not possess properties or stand in relations (Bergmann 1999, pp. 125-126, Markosian 2004, p. 52, Hinchliff 1996, pp. 124-126 ). This form of presentism (at least with regard to relations) is motivated by commitment to the Principle of Relations (PR) (which Crisp (2005, p. 5) claims is a 'truism'): the intuitive idea that all relations are existence 
Penultimate version, to appear in Southern Journal of Philosophy in 2013. Please cite published paper.

entailing, where a relation $N$ is existence entailing iff necessarily, $x N y$ only if $x$ and $y$ exist (Bigelow 1996, p. 37).

If $\mathbf{P R}$ is true and the past does not exist, then past things cannot serve as the relata in any relations. The trouble then for the tensed supervenience view is that it denies $\mathbf{P R}$ and, with it, serious presentism. It is commonly thought however that the rejection of serious presentism leads to an unattractive Meinongian metaphysics (see, for instance, Brogaard (2006, p. 195), Bergmann (1999) and Markosian (2004, p. 52)), according to which there are past things that instantiate fundamental properties and serve as the relata in cross-temporal relations, it is just that they do not exist. Presentists however are not generally willing to adopt Meinongianism with regard to the past, for two reasons. First, Meinongianism is a deeply counterintuitive view. Hence, combining presentism with Meinongianism about the past challenges the presentist's right to call her view the intuitive model of time. Second, as some philosophers have argued, once one has bought into Meinongianism with regard to nonpresent things, there no longer appears to be any clear distinction between presentism and non-presentism to be drawn (Keller 2004, pp. 89-91, Lewis 2004a, pp. 7-11), an outcome that many presentists find objectionable.

Of course, this difficulty for the tensed supervenience view is an instance of a much more general problem facing presentism: namely, the problem of cross-time relations. The basic idea behind the problem of cross-time relations is that there are metaphysical features of the world that seem to require relations that possess at least one past thing as relatum, and so the existence of the relevant features undercuts the truth of (serious) presentism. The problem can be stated in argument form as follows: 
Penultimate version, to appear in Southern Journal of Philosophy in 2013. Please cite published paper.

\section{The Problem of Cross-Time Relations ${ }^{7}$}

$\left(\mathrm{P} 1^{*}\right) \quad$ All and only present things exist [from presentism]

$(\mathrm{P} 2 *) \quad$ There are metaphysical features of the world that require the existence of cross-time relations (relations that have, as one of their relata, non-present things) [assumption]

$\left(\mathrm{P} 3^{*}\right) \quad$ If there are cross-time relations, then the non-present relata in those relations exist [from PR]

$(\mathrm{P} 4 *) \quad$ It is not the case that all and only present things exist [from P2* and P3*]

$(\mathrm{C} 1 *) \quad$ Therefore, presentism is false [from $\mathrm{P} 1 *$ and $\mathrm{P} 4 *$ ]

Given that the problem facing the tensed supervenience version of truthmaking is an instance of this general argument, one might simply defer to this more general problem, arguing that whatever the correct solution is to the problem of cross-time relations, that solution can be used to elucidate the sense in which the truth of past-directed propositions supervenes on the past. Hence, the problem raised here for the tensed supervenience view is not a special problem for that view, and so it is not a problem that the proponent of such a view needs to address.

But this appears incorrect. That is because the standard response to the problem of cross-time relations amongst presentists will not work for the cross-time supervenience of

\footnotetext{
${ }^{7}$ For further discussion of the problem of cross-time relations see Bigelow (1996), De Clercq (2006) Markosian (2004), Adams (1989), Sider (1999, pp. 327-329), Chisholm (1990), Davidson (2003), Crisp (2005), Bourne (2006, pp. 95-115), Baron (2012b), and Brogaard (2006).
} 
Penultimate version, to appear in Southern Journal of Philosophy in 2013. Please cite published paper.

truth on past being, and so the problem does appear to be a special problem for the tensed supervenience view. According to the standard response to the problem of cross-time relations one rejects $\mathrm{P} 2 *$ : the idea that there are metaphysical features of the world that require cross-time relations. Rather, although the presentist accepts the existence of the relevant metaphysical features, she argues that for any feature of the metaphysics $M$, which prima facie requires a cross-time relation, there is an analysis of $M$ available that allows one to say that $M$ exists even though there are no cross-time relations. The presentist then proceeds to provide an analysis along these lines for each $M .^{8}$

The trouble with the standard solution to the problem of cross-time relations in the present context is that, when providing an analysis of any given $M$, one generally appeals to true propositions about the past to give the relevant analysis. ${ }^{9}$ For example, suppose that Suzy is taller than Billy. If Suzy is taller than Billy then that is in virtue of a 'taller than' relation. Moreover, if Billy is wholly past and Suzy is present then such a relation, it would seem, is a cross-time relation. However, according to Bourne's (2006, pp. 97-98) presentist-friendly analysis of 'being taller-than', all we require for Suzy to be taller than Billy is the truth of two propositions: the proposition that Billy was $170 \mathrm{~cm}$ (which is a proposition concerning the past) and the proposition that Suzy is, now, $180 \mathrm{~cm}$. No relation and so no cross-time relation is required. ${ }^{10}$

\footnotetext{
${ }^{8}$ A view along these lines is defended by Bourne (2006, pp. 95-113), De Clercq (2006), Bigelow (1996, pp. 4749) and, perhaps, Markosian (2004, pp. 60-62).

${ }^{9}$ This view is most clearly defended by Bourne (2006, pp. 110-115), Crisp (2005, pp. 16-17), De Clercq (2006, pp. 388-389), McDaniel (2009, p. 328) and (in some form) by Sider (1999, pp. 12-16) (although Sider is not a presentist).

${ }^{10}$ Actually, Bourne's analysis is framed in terms of facts rather than propositions. For present purposes I assume that facts just are true propositions. Admittedly, this assumption is controversial. An alternative view would be that facts are not true propositions but, rather, constitute the supervenience base for the truth of propositions. On
} 
Penultimate version, to appear in Southern Journal of Philosophy in 2013. Please cite published paper.

Similar considerations apply to causation. Presentists usually respond to the causal form of the problem of cross-time relations by offering a presentist-friendly analysis of causation according to which causation is not a relation. This typically proceeds by analysing causation using a counterfactual theory of causation (Crisp 2005, pp. 5-17, Bourne 2006, pp. 110-115, McDaniel 2009, pp. 60-62). ${ }^{11}$ For, as Lewis (2004b, p. 283) points out in his discussion of absence causation, "the counterfactual analysis escapes the problem [of missing relata] because, when the relata go missing, it can do without any causal relation at all."

But this analysis of causation requires true claims concerning the past also. For example, suppose that some present $R$ depends causally on some past $C$. $R$ depends causally on $C$ on Lewis' (1973) counterfactual theory of causation if the following two counterfactuals hold:

(CF1) If $C$ had not occurred, $R$ would not have occurred

(CF2) If $C$ had occurred, $R$ would have occurred

If (CF2) is true actually (and presentism is true actually) then it must be true to say both that $C$ occurred actually and that $R$ occurs actually, in the present. If these claims are true however, then the causal dependence of $R$ on $C$ rests on the truth of (CF1). But,

this alternative view, Bourne's analysis is best thought of as analysing cross-time relations in terms of existing surrogates for the past (namely, primitively tensed facts that exist in the present and which are not themselves past things). A view along these lines is discussed in $\$ 4$ and rejected on the grounds that analysing tensed supervenience in terms of presently existing things collapses that view into the standard response to the truthmaker objection.

${ }^{11}$ Of course, there are other presentist-friendly options for analysing causation available. However, as Bourne's (2006, pp. 110-115) discussion of the alternatives shows, each of these options requires the truth of propositions concerning the past as well. 
Penultimate version, to appear in Southern Journal of Philosophy in 2013. Please cite published paper.

according to the standard Lewis-Stalnaker semantics for subjunctive conditionals (appropriately modified to suit the causal dependence of the present on the past), (CF1) is true iff in the closest possible world to the actual world in which $C$ did not occur in the past, $R$ does not occur in the present. Therefore, so long as there is a closest world to the actual world in which the proposition that $C$ did not occur is true and the proposition that $R$ does not occur is true, then (CF1) holds and $R$ depends causally on $C$ (mutatis mutandis for (CF2) if $R$ and $C$ do not occur actually). Once again, no relation and so no cross-time relation is required. Nevertheless, for both $(\mathrm{CF} 1)$ and $(\mathrm{CF} 2)$ true propositions concerning the past are essential.

Thus, given that the standard response to the problem of cross-time relations typically appeals to true propositions concerning the past to analyse those features that seem to require cross-time relations, that response cannot be used to flesh out the tensed supervenience view. For the truth of such claims is precisely what is at stake when offering the tensed supervenience view as a solution to the truthmaker objection in the first place, and so crosstemporal supervenience cannot be analysed in this fashion, on pain of circularity. ${ }^{12}$ The central question then is whether there is some further analysis of cross-temporal

\footnotetext{
${ }^{12}$ One might disagree in the causation case, arguing that the closest possible world to the actual world need not be a presentist world. But if it were to turn out that the closest possible world is a non-presentist world, then one would avoid the need to invoke any special account of the supervenience of truth on past being in such worlds. However, most presentists assume that presentism is a necessary truth (see for example Markosian (2004, p. 47, fn. 41), Sider (1999, p. 325), Baia (forthcoming, fn. 6), Davidson (2003, p. 90, fn. 91), Hestevold (2008, p. 325) and Bergmann (1999, p. 123)) and so the closest worlds will all be presentist worlds. Even if this were not the case, it seems reasonable to suppose that for any three worlds $W, V$ and $Z$ if $W$ and $Z$ are presentist worlds and $V$ is a non-presentist world and the three worlds are alike in other respects, then $W$ will be more similar to $Z$ than $V$ is.
} 
Penultimate version, to appear in Southern Journal of Philosophy in 2013. Please cite published paper.

supervenience available, one that might avoid commitment to cross-time relations without presupposing the truth of past-directed propositions. This question will be taken up in $\S 4$.

\section{Synchronic Relations}

As previously discussed, one form of the standard response to the truthmaker objection invokes the existence of tensed properties: properties that are presently instantiated and that stand proxy for past things. In his original discussion of this approach to the truthmaker objection, Bigelow (1996, pp. 46-47) also puts these tensed properties to work in answering the problem of cross-time relations. According to Bigelow, those metaphysical features of the world that seem to require cross-time relations can be analysed in terms of synchronic relations between presently instantiated properties.

For example, suppose that Suzy threw a rock at a bottle, smashing it to pieces. If presentism is true then because Suzy's throwing is past it cannot serve as a relatum in the causal relation between the throwing and the smashing. Consequently, on Bigelow's view, a tensed property is invoked for Suzy's throwing that can 'stand in' for the missing relatum: the tensed property having been such that Suzy threw a rock, instantiated by the world itself. Causation more generally then is recovered by systematically introducing surrogates for the past relata in causal relations in this fashion, and then treating causation as a synchronic relation either between pairs of surrogates or between surrogates and other presently existing things (such as present smashings).

This idea can then be generalised outward to other relations: for any metaphysical feature $M$ that appears to require a cross-time relation, $M$ exists in virtue of synchronic relations that have, as their relata, surrogates for the past. The idea might also be generalised to the tensed supervenience of truth on past being: the supervenience of the truth of a 
Penultimate version, to appear in Southern Journal of Philosophy in 2013. Please cite published paper.

proposition $P$ on the past is to be treated as a synchronic relation between $P$ and some existing surrogate for a past entity, a tensed property say. Since, by proceeding in this fashion, there is no need to invoke true propositions concerning the past in the analysis of tensed supervenience, the threat of circularity is avoided.

The trouble with this analysis of tensed supervenience however is that it appears to collapse the tensed supervenience solution into a form of the standard solution to the truthmaker objection discussed above. According to the current proposal, one analyses the supervenience of truth on past being as a synchronic relation between a proposition and a tensed property. But then it appears one has simply traded in tensed supervenience for the more mundane supervenience of truth on the present, since one uses precisely the same supervenience relations in both cases. Moreover, notice that this problem is not simply an artefact of using tensed properties: no matter what kind of surrogate for the past one deploys as proxy for a missing relatum, tensed supervenience becomes supervenience on surrogates for past objects in the relevant analysis. ${ }^{13}$

\footnotetext{
13 In a recent paper Brogaard (2006, pp. 197-199) extends Bigelow's view by positing presently instantiated, fundamentally tensed, monadic, relational properties. For example, consider again Suzy’s being taller than Billy. On Brogaard's view, Suzy is taller than Billy because she instantiates the primitive relational property being taller than Billy was, where this relational property is not a cross-time relation of any kind but, nevertheless, is capable of playing roughly the same role as a relation of this sort, without the need for past relata. One might coopt Brogaard's relational properties into an account of the tensed supervenience of truth on being. The idea would be to attribute certain relational properties to propositions that stand in for the supervenience relations that hold between propositions and the past. But this view suffers from precisely the same difficulty that faced the Bigelow-style attempt to understand tensed supervenience: if propositions about the past, along with the properties they possess, do all of the relevant work, then tensed supervenience is nothing more than supervenience on abstract objects.
} 
Penultimate version, to appear in Southern Journal of Philosophy in 2013. Please cite published paper.

\section{Negative Existentials}

So far I have argued that one cannot analyse the cross-temporal supervenience of truth on being in terms of true propositions concerning the past (because that is fundamentally circular), or in terms of some further feature of the presentist's ontology (because that collapses the view back into the standard response to the truthmaker objection). This is troubling because at best, when attempting to resolve the problem of cross-time relations by reanalysing those metaphysical features that seem to require cross-time relations in a presentist-friendly manner, the presentist has at her disposal things that presently exist along with true propositions concerning the past. Since both fail to support tensed supervenience, it appears that the presentist simply does not have the resources available to provide a viable analysis of that notion.

At this juncture however, the proponent of the tensed supervenience view might try a somewhat different approach. She might accept that there is, as yet, no good non-relational analysis of tensed supervenience available. She might then argue that there are nevertheless good reasons for thinking that the supervenience view of truthmaking (characterised by SP) already permits the supervenience of truth on being without supervenience relations. Hence, although the task of determining the correct, non-relational analysis of the supervenience of truth on being is a substantial one, an analysis along these lines is required of the proponent of SP anyway. Thus, the proponent of the tensed supervenience account can simply defer to whatever that analysis might turn out to be, in the end, applying it to the supervenience of truth on the past. Hence, again, if there is a problem here it is a general problem and not one for the tensed supervenience account per se. 
Penultimate version, to appear in Southern Journal of Philosophy in 2013. Please cite published paper.

Alex Baia (forthcoming) develops an approach of this kind, offering an argument to the effect that SP does not require supervenience relations generally, but that truth supervenes on the ontology all the same. Baia writes:

In particular, the advocate of mere $[\mathbf{S P}]$ is in no position to complain that, on presentism, some truths are unanchored. On mere [SP], that there are no unicorns is also unanchored, but presumably the advocate of mere $[\mathbf{S P}]$ does not believe that negative existentials are thereby counterexamples to Grounding. In short, it is implausible that Anchoring is necessary for Grounding, for it is plausible that some truths are grounded yet unanchored. (Baia forthcoming).

For Baia (forthcoming), grounding is the idea that "every true proposition depends for its truth on the world". SP, according to Baia, is a precisification of grounding. Thus, the general idea indicated in the above quotation is the following: because the truth of negative existentials does not require relations to existing things (which is what Baia seems to mean by 'anchoring'), but depends on the ontology all the same, the proponent of SP is already committed to thinking that the existence of such relations is not necessary for the dependence of truth on being. Thus, using SP to elucidate the sense in which propositions about the past are grounded, does not also force one to accept that propositions about the past are anchored and so the objection to the tensed supervenience view outlined in $\S 3$ is misplaced.

The central step in Baia's argument appears to be the claim that "on mere [SP], that there are no unicorns is also unanchored, but presumably the advocate of mere $[\mathbf{S P}]$ does not believe that negative existentials are thereby counterexamples to Grounding." In order for this step to be plausible, the proponent of SP must take the proposition that there are no unicorns to be both grounded and unanchored. Since grounding is being precisified as 
Penultimate version, to appear in Southern Journal of Philosophy in 2013. Please cite published paper.

supervenience, if the proposition that there are no unicorns is grounded then this implies that its truth supervenes on being and thus that it possesses a supervenience base. But what is the supervenience base for that proposition? There appear to be just three options. First, the supervenience base might correspond to some existing thing. Second, the supervenience base might correspond to some absence and, third, the supervenience base might correspond to nothing at all. Let us consider each of these in turn, in order to see whether there is any basis for thinking that there are no unicorns is both grounded and unanchored, as Baia suggests.

Suppose that there are no unicorns supervenes on some existing thing. Because $\mathbf{S P}$ is a global supervenience thesis (Merricks 2007, pp. 71-72) (it maintains that one cannot change the truth of a claim without making some difference to the world) one natural candidate for the supervenience base for true negative existential propositions is the world itself, where the proposition that there are no unicorns, say, supervenes on the world iff (using the schema afford by SP) for any worlds $W$ and $V$, if that proposition is true at $V$ and false at $W$, then unicorns exist at $W$ but not at $V$. Although inititally compelling, this account of the supervenience base of negative existentials faces serious difficulties (see Parsons (2006)). But we need not defend the position here. Rather, the point to focus on is whether any position along these lines (whereby true negative existentials supervene on existing things) provides a basis for thinking that negative existentials are both grounded and unanchored. The answer, I'm afraid, is 'no': if the supervenience base for a negative existential proposition is an existing thing, then although the proposition is grounded via supervenience, there is no reason at all to think that it is unanchored. After all, the relevant supervenience base exists and so is there to do any anchoring work that might be required.

This brings us to the second option. On this option, the truth of the proposition that there are no unicorns supervenes on some absence. This idea can be motivated by the following quote from Lewis (2001, p. 610): 
Penultimate version, to appear in Southern Journal of Philosophy in 2013. Please cite published paper.

[SP] allows truths to have truthmakers, but also it allows them to be true just because they lack falsemakers. The simplest case is that of a negative existential: the proposition that there are no unicorns, say. It is true in the actual world just because there are no unicorns to make it false. In any world where it is false, certain things would have to exist which in actuality do not exist, namely one or more unicorns.

The key to this quote is the claim that, under SP, that there are no unicorns is true actually just because there are no unicorns to make it false. For if the proposition at issue is true because there are no unicorns, then it appears that the truth of that proposition at the actual world is grounded in an absence: the absence of a unicorn.

If the absence of a unicorn is the correct supervenience base for the proposition that there are no unicorns, then the claim is clearly unanchored. For anchoring requires relations, and relations are existence entailing. So the proposition that there are no unicorns cannot be anchored, unless one is willing to reify absences (thereby committing to their independent existence as entities), which, as Lewis (2010, pp. 610-612) argues, one should not be willing to do. But if that is along the right lines, then prima facie this second option offers everything that Baia requires: that there are no unicorns is grounded via its supervenience on some absence, which also means that it is unanchored, because absences do not exist as entities.

But notice that if the supervenience of that there are no unicorns on some absence is a genuine instance of the dependence of truth on being (i.e. grounding), then absences must be a part of the ontology in some sense. After all, something cannot do grounding work unless it has some positive ontological status. But absences cannot be existing things, since that would collapse the current proposal into the first proposal tabled above. So one must be willing to accept that there are absences, which serve as the supervenience base for negative 
Penultimate version, to appear in Southern Journal of Philosophy in 2013. Please cite published paper.

existentials and which are part of the ontology, but which do not exist. Unfortunately, I can only see one way to make sense of this idea, and that is to endorse a Meinongian ontology, according to which there are things that do not exist. But proponents of SP should not, in general, be committed to Meinongianism and for good reason: as already noted, Meinongianism is an extremely controversial view, and so it would be quite bad if SP were to require it. So although this second option for elucidating the supervenience base for negative existentials gets Baia everything he requires, it is extremely costly.

This leaves us with the third option. According to the third option, the proposition that there are no unicorns supervenes for its truth on nothing at all: not even an absence. The proposition simply lacks a supervenience base, but is true nonetheless. On this option, the proposition that there are no unicorns is unanchored: if the proposition lacks a supervenience base, then it cannot be anchored to such a base. But if the proposition at issue lacks a supervenience base, then it is not grounded either, because (again) grounding is precisified as supervenience on the Baia view, and so it is a minimum requirement of grounding under $\mathbf{S P}$ that a proposition have a supervenience base. So while negative existentials are unanchored on this third option, this is gained only at the cost of grounding. Thus, this option cannot provide support for Baia's claim that the proposition that there are no unicorns is both unanchored and grounded.

It appears then that the three options for identifying a supervenience base for the proposition that there are no unicorns under SP fail to give Baia what he needs. Either the supervenience base exists, in which case there is no reason to think that the claim is unanchored; or the supervenience base does not exist, in which case one excises anchoring at the cost of Meinongianism; or there is no supervenience base at all, in which case although the proposition that there are no unicorns is unanchored, it is also ungrounded. But these three options appear exhaustive: one of these must be the correct account of negative 
Penultimate version, to appear in Southern Journal of Philosophy in 2013. Please cite published paper.

existentials under SP. But if so, then unless one is willing to be a Meinongian, it appears that negative existentials just do not provide the right sort of precedent for a non-relational notion of supervenience; they do not appear to be cases of supervenience and thus grounding without anchoring.

Of course, one might simply bite the bullet on Meinongianism. This is certainly something that Baia could try, but I think it will be a hard sell, given how controversial that view is. Besides, adopting Meinongianism does not appear to be a good strategy for preserving tensed supervenience. As already noted, Meinongianism alone is enough to solve the truthmaker objection. So if one is willing to buy into Meinongianism then one has no need to preserve tensed supervenience. One may as well simply give up on tensed supervenience and be a Meinongian presentist - a view that, as already noted, most presentists abhore.

The only other way out of the difficulty is to maintain that there is more to grounding than supervenience alone. For if one takes this line, then one can take the third of the three options outlined above: one can maintain that negative existentials lack a supervenience base and so are unanchored, but such propositions are grounded all the same, because there is something about grounding that is not captured by supervenience, and this 'something extra' accounts for the manner in which the truth of a negative existential depends on being.

But I think that a similar three-pronged difficulty to the one outlined above can be raised against any more generalised grounding view. For consider: what are the ontological grounds for the proposition that there are no unicorns? There are three options: (i) the grounds are existing things, (ii) the grounds are non-existent things such as absences or (iii) the grounds are nothing at all. Once again, it is only (ii) that seems to provide a basis for thinking that negative existential propositions are grounded but unanchored. However, as with the original problem, (ii) commits one to Meinongianism. 
Penultimate version, to appear in Southern Journal of Philosophy in 2013. Please cite published paper.

So it appears doubtful that "on mere [SP], that there are no unicorns is also unanchored, but presumably the advocate of mere [SP] does not believe that negative existentials are thereby counterexamples to Grounding". If the proponent of SP thinks that there are no unicorns is unanchored then, unless she is willing to buy into the view that true negative existentials supervene on things that don't exist, she likely thinks that there are no unicorns does not supervene for its truth on anything and so is ungrounded. On the other hand, if the proponent of SP thinks that there are no unicorns is grounded, then she likely thinks that it supervenes, for its truth, on existing things, in which case she probably thinks that the relevant claim is anchored, because its supervenience base exists (or, at least, there appears to be no reason for her to think that the claim is unanchored, as Baia suggests). Either way, this central step in Baia's argument appears flawed.

Of course, one could try and revive the broad strategy under consideration (of which Baia's argument is an instance) by offering a further reason for thinking that, under SP, true propositions generally do not require anchoring. Can such a general reason be provided? Perhaps. But Baia does not offer one, and I do not see how to develop one either, for the reasons offered in §3: SP and thus tensed $\mathbf{S P}$ require supervenience, and supervenience is a relational notion, one that presentists cannot easily analyse away.

\section{Conclusion}

I have argued that a fundamentally tensed approach to the truthmaker solution facing presentism is implausible. According to this approach, the truth of propositions concerning the past is taken to supervene on past being. I argued that this approach requires the existence of cross-time supervenience relations and thus forces presentists to give up on serious presentism, something that most presentists are not prepared to do. I showed that the need for 
Penultimate version, to appear in Southern Journal of Philosophy in 2013. Please cite published paper.

cross-time supervenience relations cannot be avoided by re-analysing cross-temporal supervenience in a presentist-friendly manner. I also showed that one cannot resist the demand for cross-temporal supervenience relations by using the supervenience of true, negative existential propositions on being as a precedent. This is important because, in conjunction with the failure of the standard solution to the truthmaker objection, the failure of the tensed supervenience solution to that argument forces the presentist toward the unattractive conclusion that propositions concerning the past are false. ${ }^{14}$

\section{Works Cited}

Adams, Robert. M. “Time and Thisness.” In Themes from Kaplan, edited by Joseph Almog, John Perry and Howard Wettstein, 23-42. Oxford: Oxford University Press, 1989. Armstrong, David. Truth and Truthmakers. Cambridge: Cambridge University Press, 2004. A World of States of Affairs. Cambridge: Cambridge University Press, 1997.

Baia, Alex. "Presentism and the Grounding of Truth." Philosophical Studies (forthcoming), doi: 10.1007/s11098-011-9711-8.

Baron, Sam. "Presentism, Truth and Supervenience.” Ratio (2012a), doi: 10.1111/j.14679329.2011.00523.x.

_ "Presentism and Causation Revisited." Philosophical Papers 41, 1 (2012b): 1-21.

\footnotetext{
${ }^{14}$ Thanks are due to Kristie Miller, David Braddon-Mitchell, Huw Price and especially Jamin Asay for many useful discussions of presentism and truthmaking. Research on this paper was partly funded by a Templeton Foundation Grant held jointly by Alex Holcombe, Kristie Miller, Huw Price and Dean Rickles.
} 
Penultimate version, to appear in Southern Journal of Philosophy in 2013. Please cite published paper.

Beebee, Helen and Dodd, Julian. "Introduction.” In Truthmakers: The Contemporary Debate, edited by Helen Beebee and Julian Dodd, 1-16. Oxford: Oxford University Press, 2005.

Bergmann, Michael. “(Serious) Actualism and (Serious) Presentism.” Noûs 33, 1 (1999): $118-132$.

Bigelow, John. "Presentism and Properties.” Noûs 30, Supplement: Philosophical Perspectives, 10 (1996): 35-52.

The Reality of Numbers: A Physicalist's Philosophy of Mathematics. Oxford: Oxford University Press, 1988.

Bigelow, John., and McKinnon, Neil. "Presentism, and Speaking of the Dead." Philosophical Studies (forthcoming), doi: 10.1007/s11098-011-9717-2.

Bourne, Craig. A Future for Presentism. Oxford: Oxford University Press, 2006.

Brogaard, Berit. “Tensed Relations.” Analysis 66, 3 (2006): 194-202.

Cameron, Ross. "How to Be a Truthmaker Maximalist.” Noûs 42, 3 (2008): 410-421.

— “Truthmaking for Presentists." In Oxford Studies in Metaphysics Vol. 6, edited by Karen Bennett and Dean W. Zimmerman, 55-101. Oxford: Oxford University Press, 2011.

Caplan, Ben and Sanson, David. "Presentism and Truthmaking." Philosophy Compass 6, 3 (2011): 196-208.

Chisholm, Roderick. M. “Referring to Things That No Longer Exist.” Philosophical Perspectives 4 (1990): 546-556.

Crisp, Thomas. “On Presentism and Triviality." In Oxford Studies in Metaphysics Vol. 1, edited by Dean W. Zimmerman, 15-20. Oxford: Oxford University Press, 2004a.

__ "Presentism and "Cross-Time" Relations." American Philosophical Quarterly 42, 1 (2005): 5-17. 
Penultimate version, to appear in Southern Journal of Philosophy in 2013. Please cite published paper.

_—Presentism and the Grounding Objection." Noûs 41, 1 (2007): 90-109.

— "Reply to Ludlow." In Oxford Studies in Metaphysics Vol. 1, edited by Dean W. Zimmerman, 37-46. Oxford: Oxford University Press, 2004b.

Dainton, Barry. Time and Space. Chesham: Acumen Press, 2001.

Davidson, Michael. "Presentism and the Non-Present." Philosophical Studies 113, 1 (2003): $77-102$.

De Clercq, R. "Presentism and the Problem of Cross-time Relations." Philosophy and Phenomenological Research 72, 2 (2006): 386-402.

Hestevold, H. Scott. "Presentism: Through Thick and Thin.” Pacific Philosophical Quarterly 89, 3 (2008): 325-347.

Hinchliff, Mark. "The Puzzle of Change.” Philosophical Perspectives 30 (1996): 119-136.

Keller, Simon. "Presentism and Truthmaking." In Oxford Studies in Metaphysics Vol. 1, edited by Dean Zimmerman, 83-107. Oxford: Oxford University Press, 2004.

Kierland, Brian and Monton, Bradley. "Presentism and the Objection from BeingSupervenience.” Australasian Journal of Philosophy 85, 3 (2007): 485-497.

Lewis, David. “Causation.” Journal of Philosophy 70, 17 (1973): 556-567.

__ “Tensed Quantifiers.” In Oxford Studies in Metaphysics Vol. 1, edited by Dean Zimmerman, 3-15. Oxford: Oxford University Press, 2004a.

__ “Truthmaking and Difference-Making." Nô̂s 35, 4 (2001): 602-615.

_ "Void and Object." In Causation and Counterfactuals, edited by John Collins, Ned Hall and Laurie A. Paul, 277-290. Cambridge: MIT Press, 2004b.

Liggins, David. “Truthmakers and Explanation.” In Truthmakers: The Contemporary Debate, edited by Helen Beebee and Julian Dodd, 105-115. Oxford: Oxford University Press, 2005. 
Penultimate version, to appear in Southern Journal of Philosophy in 2013. Please cite published paper.

Ludlow, Peter. "Defining Presentism." In Oxford Studies in Metaphysics Vol. 1, edited by Dean W. Zimmerman, 21-36. Oxford: Oxford University Press, 2004.

Markosian, Ned. “A Defense of Presentism.” In Oxford Studies in Metaphysics Vol. 1, edited by Dean Zimmerman, 47-82. Oxford: Oxford University Press, 2004.

Mason, Franklin. “What Is Presentism?” Southern Journal of Philosophy 44, 1 (2006): 107128.

McDaniel, Brannon. "Presentism and Absence Causation: An Exercise in Mimicry." Australasian Journal of Philosophy 88, 2 (2009): 323-332.

McDaniel, Kris. "Trenton Merricks' Truth and Ontology.” Philosophy and Phenomenological Research 83, 1 (2011): 203-211.

McFetridge, Ian. “Truth, Correspondence, Explanation and Knowledge.” In Logical Necessity and Other Essays, edited by John Haldane and Roger Scruton, 29-53. London: Aristotelian Society, 1990.

Merricks, Trenton. Truth and Ontology. New York: Oxford University Press, 2007.

Parsons, Josh. “Negative Truths from Positive Facts?” Australasian Journal of Philosophy 84, 4 (2006): 591-602.

Putnam, Hilary. “Time and Physical Geometry.” Journal of Philosophy 64, 8 (1967): 240 247.

Restall, Greg. “Truthmakers, Entailment and Necessity.” Australasian Journal of Philosophy 74, 2 (1996): 331-340.

Rhoda, Alan. R. "Presentism, Truthmakers, and God.” Pacific Philosophical Quarterly 90, 1 (2009): 41-62.

Rodriguez-Pereyra, Gonzalo. “Truthmaker Maximalism Defended.” Analysis 66, 3 (2006): $260-264$. 
Penultimate version, to appear in Southern Journal of Philosophy in 2013. Please cite published paper.

Sanson, David and Caplan, Ben. "The Way Things Were." Philosophy and Phenomenological Research 81, 1 (2010): 24-39.

Schaffer, Jonathan. "Truth and Fundamentality: On Merricks's Truth and Ontology.” Philosophical Books 49, 4 (2008): 302-316.

Sider, Theodore. "Presentism and Ontological Commitment." The Journal of Philosophy 96, 7 (1999): 325-347.

_ Four-Dimensionalism: An Ontology of Persistence and Time. Oxford: Oxford University Press, 2003.

__ "Quantifiers and Temporal Ontology." Mind 115, 457 (2006): 75-97.

Smith, Barry. “Truthmaker Realism.” Australasian Journal of Philosophy 77, 3 (1999): 274291.

Tallant, Jonathan. “Ontological Cheats Might Just Prosper.” Analysis 69, 3 (2009a): 422-430.

__ “Presentism and Truth-Making.” Erkenntnis 71, 3 (2009b): 407-416.

Zimmerman, D. W. "The Privileged Present: Defending an "A-theory” of Time.” In Contemporary Debates in Metaphysics, edited by Theodore Sider, John Hawthorne and Dean W. Zimmerman, 211-225. Oxford: Blackwell Publishing Ltd, 2008. 